\title{
On the Risk Assessment of Storm Surge Disasters in the Coastal Areas of Qingdao
}

\author{
Song Gao ${ }^{1,2}$, Shan Zhong ${ }^{1,2}$, Xihu Lian ${ }^{1,2}$, Lingjuan $\mathrm{Wu}^{1,2}$, Tao Bai ${ }^{1,2}$, Yaru $\mathrm{Li}^{1,2}$ \\ ${ }^{1}$ North China Sea Marine Forecasting Center of State Oceanic Administration, Qingdao 266061, China \\ ${ }^{2}$ Shandong Provincial Key Laboratory of Marine Ecological Environment and Disaster Prevention and \\ Mitigation, Qingdao 266061, China
}

\section{青岛市沿海地区风暴潮灾害风险评估研究}

\author{
高松 ${ }^{1,2}$, 钟山 ${ }^{1,2}$, 连喜虎 1,2 , 吴玲娟 ${ }^{1,2}$, 白涛 ${ }^{1,2}$, 李亚汝 ${ }^{1,2}$ \\ 1 国家海洋局北海预报中心，山东青岛 266061 , 中国 \\ 2 山东省海洋生态环境与防灾减灾重点实验室, 山东青岛 266061, 中国
}

\begin{abstract}
Based on the regional disaster system theory, the risk and vulnerability of storm surges in the coastal areas of Qingdao are assessed quantitatively and qualitatively respectively, and a risk index system of storm surge disasters in coastal areas of Qingdao is constructed in this paper. A storm surge inundation model is employed to calculate and determine the storm surge inundation areas and depth of the maximum probability, and the risk assessment of storm surges in different regions is performed. Based on the land classification for exploitation and utilization, the vulnerability of different regions is evaluated and classified. The risk of storm surge disasters in the coastal areas of Qingdao is classified with the aid of GIS spatial analysis. This assessment and classification system is scientific and user friendly, and the assessment results can be used straightforwardly to determine the risk of a hazardbearing body, which provides guide and suggestions to hazard prevention and land utilization.
\end{abstract}

Key words: storm surges; risk assessment of hazards; Qingdao

\section{摘要}

本文基于区域灾害系统理论, 通过对风暴潮危险性的 定量评估和脆弱性的定性评估, 构建青岛市沿海地区 风暴潮灾害的风险指标体系, 通过对风暴潮危险性的 定量评估和脆弱性的定性评估。采用风暴潮漫滩模
式, 计算确定风暴潮最大可能淹没范围和淹没深度, 对不同区域风暴潮的危险性进行分析评价; 以土地开 发利用类型二级分类作为脆弱性评价指标, 对评估区 域进行定性脆弱性等级划分, 利用 GIS 的空间分析 功能进行风暴潮灾害风险等级区划。该评估系体科 学、简单、易操作, 评价结果能够很直观的判断承灾 体风险性的空间分布, 便于指导灾害风险防范和土地 利用规划。

关键词: 风暴潮; 灾害; 风险评估; 青岛市

\section{1. 引言}

台风风暴潮（文中简称 “风暴潮”) 是由于台风 过境所伴随的强风和气压骤变而引起的局部海面震 荡或非周期性异常升高（降低）现象 [1]。由风暴潮、 天文潮和近岸海浪结合引起的沿岸涨水造成的巨大 灾害, 通常称之为风暴潮灾害。风暴潮灾害是人类面 临的巨大的海洋灾害, 目前人类尚无有效的方法阻 止。风暴潮灾害的轻重, 除受风暴增水的大小和当地 天文大潮高潮位的制约外, 还取决于受灾地区的地理 位置、海岸形状和海底地形、社会及经济情况等。因 此, 客观地对风暴潮灾害的风险进行评估区划, 对防 灾减灾决策和社会经济发展具有十分重要的意义。

20 世纪 80 年代以来, 国外纷纷开展风暴潮灾 害风险研究, 已形成较为科学有效的评估理论与方 法, 并在很多沿海城市得到应用[2,3]。相比而言, 我 国风暴潮灾害风险评估研究起步较晚, 主要始于国际 减灾十年活动的启动[4-6]。国家洋局于2012年颁布了 《风暴潮灾害风险评估与技术导则 (试行)》, 并于 


\section{Risk Analysis and Crisis Response in Big Data Era (RAC-16)}

2015年进行了较大的订正, 在一定程度上为我国风暴 潮灾害风险评估研究指明了方向[7]。前人对青岛市 风暴潮风险区划研究开展了一定的工作, 取得了一些 成果, 但由于评估方法不统一和基础资料的缺乏, 未 能对实际的防灾减灾工作起到显著作用 [8-9]。

\section{2. 青岛市风暴潮灾害概况}

青岛市是一座海滨城市, 海岸线漫长。2014 年 青岛市经济总量达 9340 亿元, 常住人口 1000 余万 [10]。在其辖的 6 个市辖区和代管的 4 个县级市, 中 有 8 个区域存在发生风暴潮灾害的风险。根据1949 2013 年间资料统计, 青岛沿海地区的台风风暴潮灾 害, 较重 (含) 以上者平均不到 4 年发生一次, 严重 或特别严重者平均不到 8 年发生一次。其中, 8509 台风风暴潮特重灾害, 造成直接经济损失达 5.0811 亿元, 全市有 29 人死亡、 368 人受伤。9711 台风风 暴潮特重灾害, 造成船只毁坏 436 条, 房屋倒塌 1120 间, 海堤冲毁 18 处 $4.1 \mathrm{~km}$, 虾池冲毁 1.5 万亩, 伤亡 25 人 (其中死亡 5 人), 直接经济损失约 9 亿元人民 币。

表 1 风暴潮灾害风险等级与危险性等级及脆弱性范围对应关系表

\begin{tabular}{|c|c|c|c|c|}
\hline 脆弱性 & 低 (IV级) & 较低 (III级) & 较高 (II 级) & 高 ( I 级) \\
\hline 危险性 & 值域 $[0.1,0.3]$ & 值域 $(0.3,0.5]$ & 值域 $(0.5,0.8]$ & 值域 $(0.8,1]$ \\
\hline 低 (IV级) & $\begin{array}{l}\text { 低风险 } \\
\text { (IV级) }\end{array}$ & $\begin{array}{l}\text { 低风险 } \\
\text { (IV级) }\end{array}$ & $\begin{array}{c}\text { 较低风险 } \\
\text { (III级) }\end{array}$ & $\begin{array}{c}\text { 较低风险 } \\
\text { (III级) }\end{array}$ \\
\hline 较低（III级） & $\begin{array}{l}\text { 低风险 } \\
\text { ( IV级) }\end{array}$ & $\begin{array}{c}\text { 较低风险 } \\
\text { (III级) }\end{array}$ & $\begin{array}{c}\text { 较高风险 } \\
\text { ( II 级) }\end{array}$ & $\begin{array}{c}\text { 较高风险 } \\
\text { ( II 级) }\end{array}$ \\
\hline 较高 (II 级) & $\begin{array}{c}\text { 较低风险 } \\
\text { (III级) }\end{array}$ & $\begin{array}{c}\text { 较高风险 } \\
\text { ( II 级) }\end{array}$ & $\begin{array}{c}\text { 较高风险 } \\
\text { ( II 级) }\end{array}$ & $\begin{array}{l}\text { 高风险 } \\
\text { ( I 级) }\end{array}$ \\
\hline 高（I 级） & $\begin{array}{c}\text { 较低风险 } \\
\text { (III级) }\end{array}$ & $\begin{array}{c}\text { 较高风险 } \\
\text { ( II 级) }\end{array}$ & $\begin{array}{l}\text { 高风险 } \\
\text { ( I 级) }\end{array}$ & $\begin{array}{l}\text { 高风险 } \\
\text { ( I 级) }\end{array}$ \\
\hline
\end{tabular}

\section{2. 数据处理}

本文的资料和数据主要围绕风暴潮灾害危险性 评价和脆弱性评价 2 个方面进行收集和整理。其中, 青岛市 1:5 万 DEM 数据, 测量时间为 2010 2012 年。 水深数据来源于电子海图和调查数据。岸线数据利用 高分辨率卫星影像进行获得。防潮设施位置、高程、 海

岸属性、防潮质量等属性数据, 采用现场调查的

\section{3. 风险评估方法与数据处理}

\section{1. 风险评估指标体系构建}

对于灾害风险系统的构成, 不同学者有不同的见 解[11-14]。本文基于区域灾害系统理论, 构建风暴潮 灾害的风险指标体系, 通过对风暴潮危险性的定量评 估和脆弱性的定性评估, 进行风暴潮灾害风险评价指 标的半定量化分析后, 利用 GIS 的空间分析功能将 各评价指标按期权重进行叠加分析, 并进行风暴潮灾 害风险等级区划。

风险等级评估公式为:

$$
\mathrm{R}=\mathrm{H} \times \mathrm{V}
$$

其中, R (Risk) 代表风险, H（Hazard）代表危险 性等级分布, V (Vulnerability) 代表脆弱性等级分布。 “ $\times$ ” 风险等级识别矩阵。基于风暴潮灾害危险性等 级评估结果、脆弱性等级评估结果, 以及二者与灾害 风险等级的对应关系 (表 1), 确定评估空间单元的 风险等级。[7]危险性等级分为 4 级, 采用淹没水深 作为指标进行危险性等级划分。脆弱性评价以土地利 用类型二级分类作为脆弱性评价指标, 对评估区域进 行定性脆弱性等级划分 (具体对应关系参见文献 7)。 
Risk Analysis and Crisis Response in Big Data Era (RAC-16)

4. 危险性评价分析

\section{1. 风暴潮数值模式设置}

本项目采用丹麦水力学研究所研制的数值模型 MIKE21FM 来计算青岛市沿海风暴潮淹没过程 [16]。 风暴潮数值模式计算海域范围为 $117^{\circ} \mathrm{E} \sim 133^{\circ} \mathrm{E}$, $22^{\circ} \mathrm{N} \sim 42^{\circ} \mathrm{N}$ (图 1), 模式采用非结构三角网格,
为了精确的模拟风暴增水淹没范围和水深, 网格在岸 线附近进行加密, 空间网格分辨率约为 $50 \mathrm{~m}$ 。海水淹 没计算范围重点考青岛市沿海 $10 \mathrm{~m}$ 高程线以下的范 围, 整个模拟区域内由 51111 个节点和 100417 个三 角单元组成, 开边界采用静压条件。采用 MIKE21 中的堤防模块, 根据青岛市各岸段防潮设施调查和收 集的防潮堤设计数据, 在模型中对每一点进行具体堤
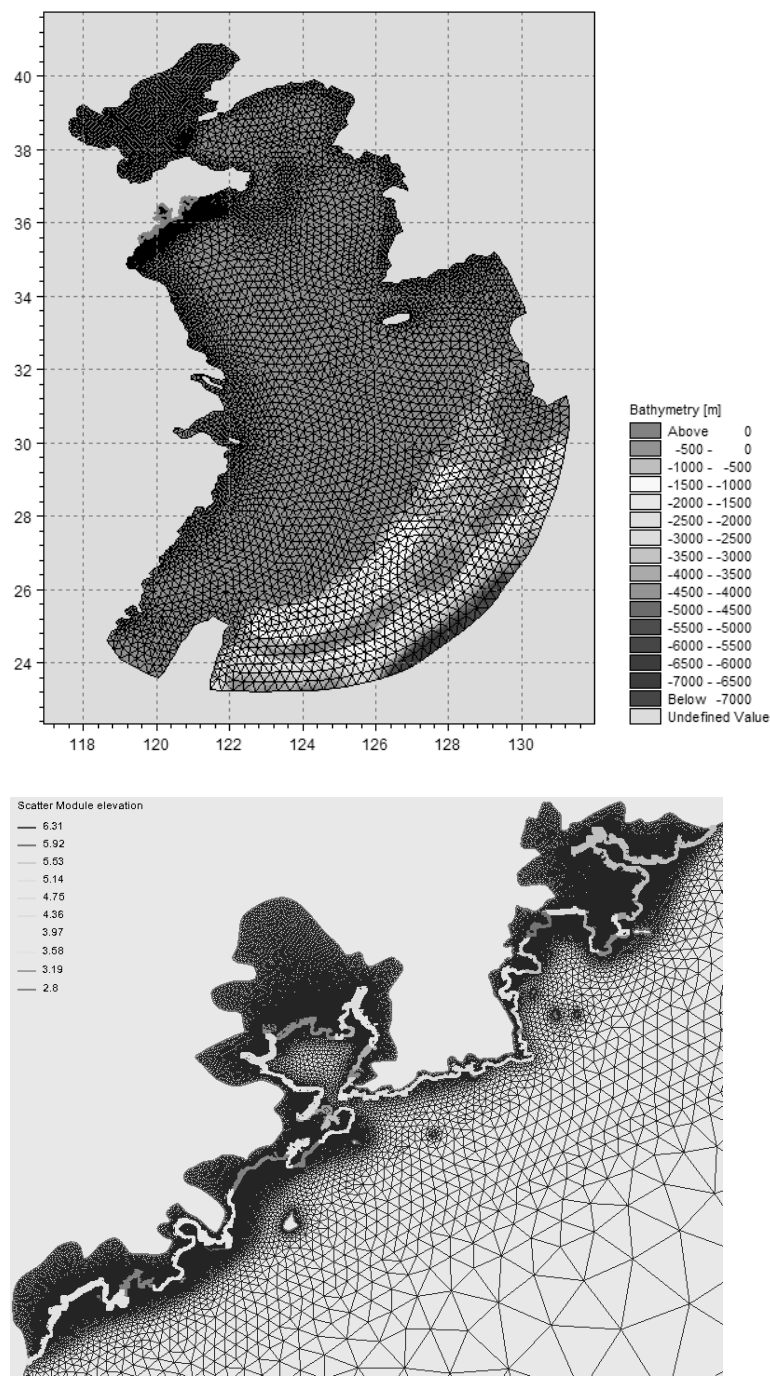

图 1 风暴潮模式网格与提防高程值图 (单位: $\mathrm{m}$ ) 
Risk Analysis and Crisis Response in Big Data Era (RAC-16)

防高程的设置。

本文基于可能最大风暴潮（ProbableMaximum Storm Surge, PMSS）方法, 设计影响青岛沿岸最大风 暴增水的台风路径集[17]。采用 CMA-STI 数据集 （1949 年 2014 年), 在 $\left(110^{\circ} \mathrm{E} \sim 130^{\circ} \mathrm{E}, 31^{\circ}\right.$ $\left.\mathrm{N} \sim 41^{\circ} \mathrm{N}\right)$ 范围内, 采用极值 I 型分布计算 1000 年 一遇最低气压值为 $894 \mathrm{hPa}$, 作为可能最大台风中心 气压。选取五号码头站作为研究区域内的代表性验潮 站, 潮位数据年限为 1990 2013 年, 取累年各月平均 天文潮 $10 \%$ 超越高潮位值为 $272 \mathrm{~cm}$, 作为天文潮潮位 起算面。

\section{2. 危险性等级评价分析}

图 2 为青岛市风暴潮危险性等级图。青岛市沿 岸区域主要高危险区分布在丁字湾西侧、鳌山湾顶 部、胶州湾西北侧及顶部、前湾港和琅躯台湾等区域。 各级危险性总影响面积总和为 $691.57 \mathrm{~km}^{2}$, I 级、II 级、III级和 IV 级危险性面积分别为 $141.22 \mathrm{~km}^{2}$ 、 $309.39 \mathrm{~km}^{2} 、 213.60 \mathrm{~km}^{2} 、 27.36 \mathrm{~km}^{2}$ 。从各区的角度来 分析，城阳区、胶州市和西海岸新区(东区)受风暴潮 淹没影响最为严重, 即墨市风暴潮淹没影响较为严 重, 崂山区、市南区、市北区和李沧区风暴潮淹没影 响相对较轻。

\section{5. 脆弱性评价分析}

本文利用青岛市第二次全国土地调查数据, 依据 文献 7 进行青岛市可能淹没范围内的脆弱性评价, 评 价结果见图 3。从图可以看出, 即墨市脆弱性部分区 域为IV级; 沿岸存在部分III级区域基本为养殖用地; 零星分布的 I 级区域, 多为村庄; 鳌山湾顶部及西侧 为青岛蓝色硅谷核心区, 大量建设临海新城, 脆弱性 I 级区域面积较大。崂山区沙子口以东岸线区域多为 IV 级脆弱性区域, 沙子口及以西至麦岛以东的海岸区 域经济相对发展较好岸段, 住宅及商服用地密集, 脆 弱性等级多为 I 级。市南区的小麦岛至团岛岸段, 经 济发达, 人口密度大, 脆弱性等级多为 I 和 II 级。胶 州湾东岸集港航、商务、旅游、休闲等功能于一体, 脆弱性等级多为 I 和 II 级。城阳区女姑河两侧区域, 脆弱性等级多为 I 和 II 级; 大姑河两侧区域, 多为养 殖区, 脆弱性等级为III级。红岛区域南侧岸段主要为 渔港码头区, 脆弱性等级多为 I 和 II 级; 红岛区北部 为高新技术产业区的中心区域, 地势低平, 建筑密集, 数条人工河道横贯其间, 该区脆弱性等级部分为 I 级、II 级, 分布在IV级区域内。胶州湾西北侧胶州市 区域是为黄岛产业配套的现代物流、生产性服务业、 新兴制造业为主的现代都市工业园区, 沿岸区域分布 I 级高脆弱区。西海岸新区(东区)前湾港区为重大港 口区域, 脆弱性等级多为 I 级; 西海岸新区(东区) 唐

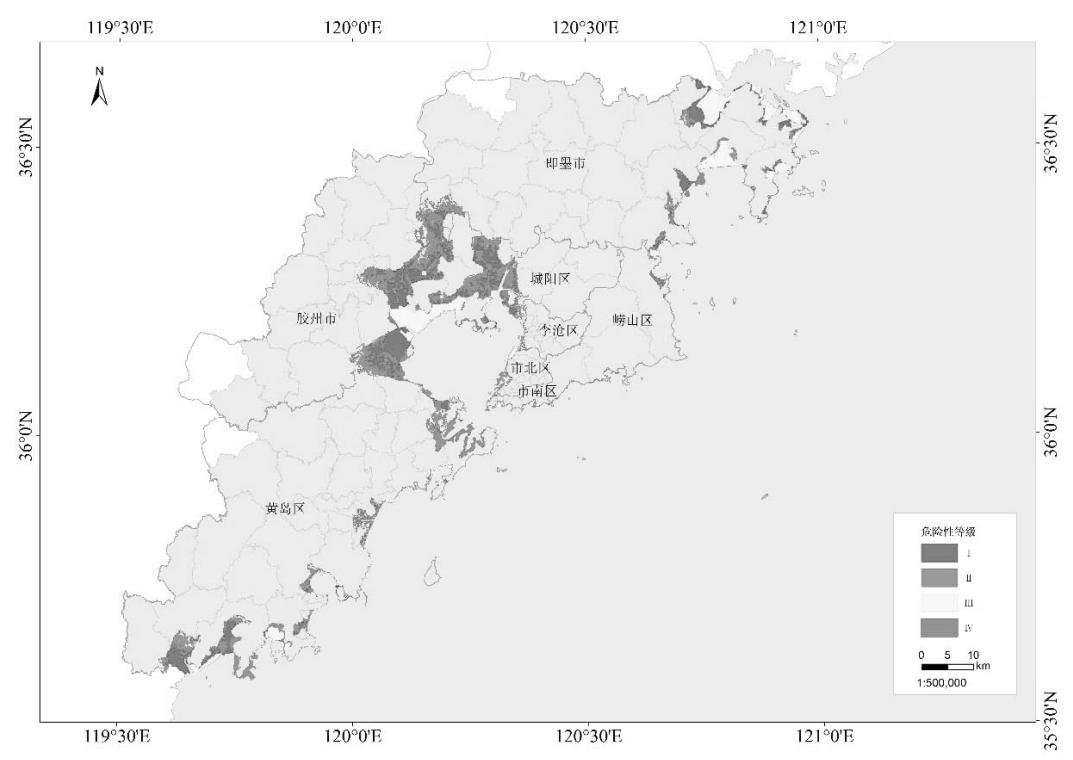

图 2 可能最大风暴潮危险性等级图 
Risk Analysis and Crisis Response in Big Data Era (RAC-16)

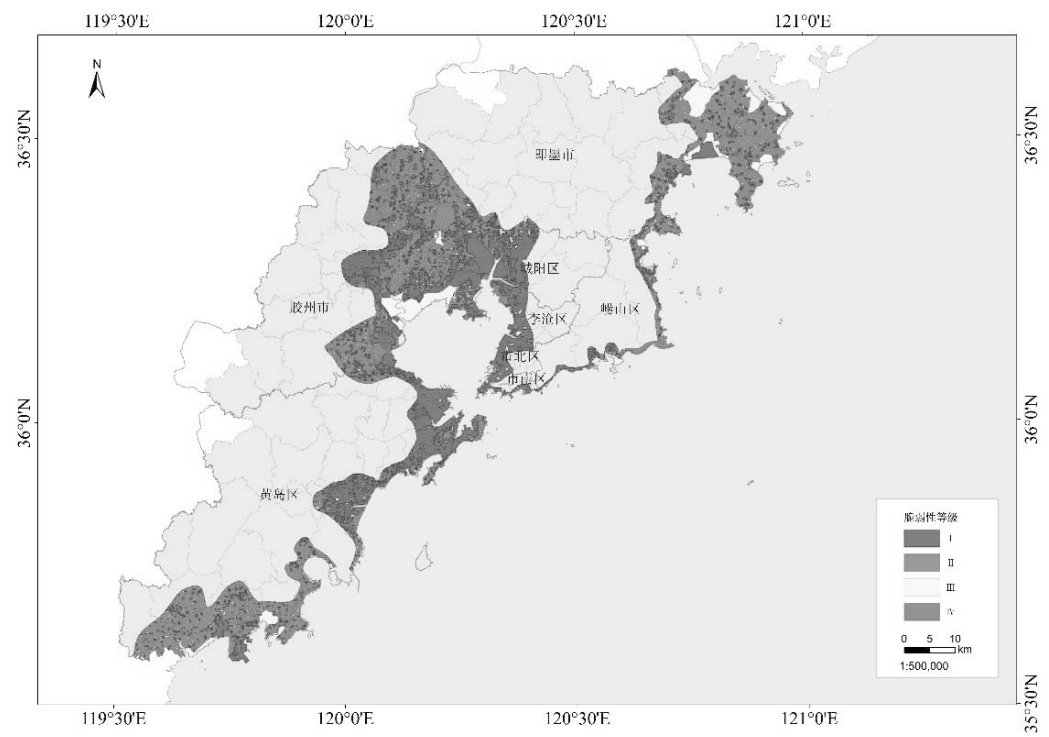

图 3 青岛市风暴潮脆弱性等级图

岛湾顶部与西岸区域为行政商贸中心区, 是青岛保税 IV 级区域, 其中董家口港区脆弱性等级为 I 级。 港区、青岛高新技术产业开发实验区, 脆弱性等级多 为 I 级; 西海岸新区(东区)原胶南区域, 多为脆弱性

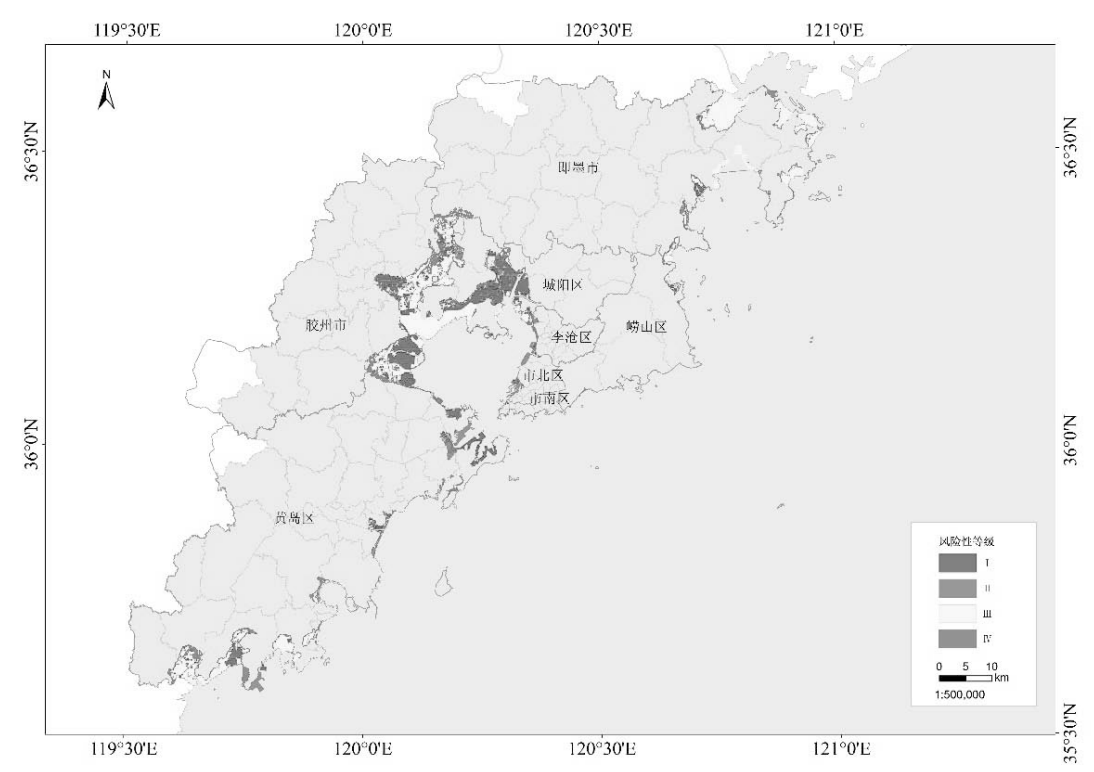

图 4 最大风暴潮风险性等级图 
Risk Analysis and Crisis Response in Big Data Era (RAC-16)

\section{6. 风险性评估与区划分析}

青岛市风暴潮灾害 I 和 II 级高风险区划主要集 中在(图 4)：1）胶州湾东北部的女沽河两岸及红岛 北侧区域, 即城阳区流亭街道和城阳街道西部区域, 棘洪滩街道西部、上马街道西部和南部和红岛街道北 部。2）胶州湾西北侧的大沽河区域, 即城阳区的河 套街道、上马街道东部、棘洪滩街道东部、李哥庄镇; 胶州市的皁安街道、云溪街道、胶东街道、九龙街道 东部及东北部, 南关街道东北部。3）胶州湾西侧的 红石崖区域, 即胶州市的九龙街道南部, 西海岸新区 (东区)的红石崖街道。4) 胶州湾西侧的前湾港区域, 即西海岸新区(东区)的黄岛街道、辛安街道东部、长 江街道东北部、薛家岛街道北部。5) 胶州湾东侧区 岸段, 即市南区的小港街道和大港街道、市北区的水 清沟和洛阳路街道西部、李沧区的振华路街道东部局 部、兴城路街道和楼山街道局部。6) 鳌山湾区域, 即即墨市的王村镇南部、温泉镇东部局部。7）黄岛 董家口港区岸段, 即西海岸新区(东区)泊里镇南侧区 域。III级较低风险区划主要集中在近岸的养殖区域, 及发生淹没但脆弱性较低的大沽河河套区域、丁字湾 西岸区域、琅邪台湾顶部区域。IV级低风险区主要分 布在淹没区域向陆的边缘地带和岸边受浪影响严重 区域。

\section{7. 讨论}

风暴潮灾害风险区划的研究旨在指导合理的土 地利用布局, 尽量降低风险, 减少损失。无论是定量 还是半定量风险评估方法, 都存在机制的解释和应用 的直观性问题。为了避免这一问题, 本文建立了以风 暴潮淹没深度为定量化危险性指标和土地利用类型 为定性脆弱性指标的风暴潮风险评估体系。该评估系 体科学、简单、易操作, 评价结果能够很直观的判断 承灾体风险性的空间分布, 便于指导灾害风险防范和 土地利用规划。该评估方法的缺点在于无法定量化评 估脆弱性, 对于如何在具体的灾害应急指挥中发挥作 用, 尚需进一步研究。

\section{参考文献}

[1] 冯士筰. 风暴潮导论. 北京: 科学出版社, 1982.

[2] Cheng X F, Sun H H, Zhang Y, Xu G L. Flood Disaster Risk Assessment and Spatial Distribution Characteristics along the Yangtze River in Anhui. Journal of Risk Analysis and Crisis Response, 4(4), $238-242$.

[3] Brian A. Colle, Frank Buonaiuto, Malcolm J. Bowman, Robert E. Wilson, Roger Flood, Robert Hunter, Alexander Mintz, and Douglas Hill. New York City's Vulnerability to Coastal Flooding Storm Surge Modeling of Past Cyclones. Bull.amer.meteor.soc, 2008, 89(6):829.

[4] 李阔, 李国胜. 广东沿海地区风暴潮易损性评估. 热带地理,2011, 31(2): 153-158, 177.

[5] 谢翠娜. 上海沿海地区台风风暴潮灾害情景模 拟及风险评估. 上海: 华东师范大学, 2010 .

[6] 曹琼珊, 基于 GIS 技术的风暴潮灾害风险评估 研究一一以舟山市定海区为例. 上海, 华东师范 大学, 2015

[7] 国家海洋局. 风暴潮灾害风险评估与区划技术 导则(试行).2015.

[8] 殷克东, 刘士彬, 王冰. 青岛近海地区风暴潮灾 害风险区划研究. 中国渔业经济, 2011, 29(1):41-47.

[9] Yuhong Zhang, qiangliu. 青岛地区风暴潮灾害 易损性风险区划建模. 海洋地质前沿, 2012, 28(9):46-53.

[10] 2015 年青岛市年鉴, 青岛市史志办公室,2015

[11] Okada N, Tatano H, Hagihara Y, et al. Integrated Research onMethodologicalDevelopment of Urban Diagnosis for DisasterRisk and its Applications. Annuals of Disaster Prevention Research Institute Kyoto University, 2004, 47C: 1-8.

[12] 张继权, 李宁. 主要气象灾害风险评价与管理 的数量化方法及其应用. 北京: 北京师范大学 出版社, 2007.

[13] 史培军. 三论灾害研究的理论与实践. 自然灾 害学报, 2002, 11(3): 1-9.

[14] UN/ISDR. Living with Risk: A GlobalReview of DisasterReduction Initiatives. United Nations Publication, 2004.

[15] http://www.typhoon.gov.cn

[16] Elsaesser B. Storm surge hind- and forecasting using Mike21FM - simulation of surges around the Irish Coast. 2010.

[17] 王喜年. 风暴潮预报知识讲座. 